\title{
New Type of Polyelectrolyte Obtained by Electron Beam Irradiation
}

\author{
G. Craciun and E. Manaila* \\ National Institute for Laser, Plasma and Radiation Physics, Electron Accelerators Laboratory, \\ 409 Atomistilor St., 077125 Magurele, Romania
}

\begin{abstract}
The paper presents the obtaining, characterization and testing of a new type of polyelectrolyte based on acrylamide, acrylic acid and sodium alginate for flocculation purposes. Two types of monomeric solutions were irradiated at room temperature and in atmospheric conditions with doses between 0.5 and $2 \mathrm{kGy}$ using the ALID 7 electron accelerator of $5.5 \mathrm{MeV}$. The flocculants were characterized in order to determine conversion coefficient, residual monomer content, intrinsic viscosity, molecular weight and radius of gyration. The flocculation characteristics were evaluated in 0.1 and $0.2 \mathrm{wt} \%$ blue kaolin suspension at room temperature.
\end{abstract}

DOI: 10.12693/APhysPolA.135.1065

PACS/topics: acrylamide, sodium alginate, irradiation, properties, flocculation

\section{Introduction}

Radiation processing offers a clean method for the preparation of novel materials for flocculation purposes. Past research has shown that, depending on the irradiation conditions, natural polysaccharides can be used for the development of many applications [1, 2]. They are natural polymers that act as bridging flocculants and can be extracted from plant cell walls, seeds, tubers or roots, seaweed etc. [2]. By grafting polyacrylamide branches on polysaccharides, the dangling grafted chains have easy approachability to the contaminants [3]. The goal of the paper is to present the obtaining, characterization and testing of a new type of polyelectrolyte obtained by electron beam irradiation, for flocculation purposes.

\section{Materials and equipments}

Irradiation was performed in atmospheric conditions and at room temperature of $25^{\circ} \mathrm{C}$, using the ALID 7 linear electron accelerator of $5.5 \mathrm{MeV}$ [4]. The EB dose rate was fixed at $2 \mathrm{kGy} / \mathrm{min}$ in order to accumulate doses between 0.5 and $2 \mathrm{kGy}$. For the samples preparation, two types of monomeric solutions were used. They have the same content of acrylamide $(2.63 \mathrm{~mol} / \mathrm{L})$, acrylic acid $(1.73 \mathrm{~mol} / \mathrm{L})$ and potassium persulfate $(925 \mu \mathrm{mol} / \mathrm{L})$ and sodium alginate in two concentrations: $1 \%$ (Sol I) and $2 \%$ (Sol II). Purification of the grafted polymers was realised in order to remove homopolymer $[5,6]$ and to separate the unreacted monomers. The grafting efficiency (GE) was calculated [6]. Sample characterization was done as in our previously work [6] in order to determine the conversion coefficient $(\mathrm{CC})$ and intrinsic viscosity $\left(\eta_{\text {intr }}\right)$. Flocculation studies were carried out on kaolin suspension

\footnotetext{
*corresponding author; e-mail: elena.manaila@inflpr.ro
}

(0.1 and 0.2 wt\%) at room temperature of $25^{\circ} \mathrm{C}$ using a standard Jar test apparatus. Flocculation efficiency was appreciated in terms of transmittance $(T)$ at $620 \mathrm{~nm}$ using a UV-VIS spectrophotometer [4].

\section{Results and discussion}

In Fig. 1 are presented the physical/chemical characteristics of the obtained polyelectrolytes. It can be seen that GE increases with increasing of the absorbed dose, presents a maximum value at $1.5 \mathrm{kGy}$, then slowly decreased. Low values of GE are commonly connected with high amounts of homopolymer [4]. It can be seen that high irradiation doses are in the benefit of both $C_{c}$ and $M_{\text {rez }}$. Samples irradiated at 1.5 and $2 \mathrm{kGy}$ have presented values of $M_{\text {rez }}$ under $0.05 \%$, the limit imposed for the acrylamide use. The results of flocculation studies for all polymer concentration and irradiation doses are presented in Fig. 2a and b).

Good results were obtained for polymer concentrations up to $5 \mathrm{ppm}$ in the case of both 0.1 and $0.2 \mathrm{wt} \%$ kaolin suspension. The best result was obtained for the type I sample irradiated at $1 \mathrm{kGy}$, for which the $T$ values remains constant (around 85.5\%) for every polymer concentration between 1 and 6 ppm (Fig. 2a). The flocculation results are clearly depreciated by doubling the kaolin concentration in the solution (Figure $2 \mathrm{~b}$ ). The results of flocculation studies versus rotation speed between 50 to $150 \mathrm{rpm}$, for all irradiation doses using a polymer concentration of $0.5 \mathrm{ppm}$ are presented in Fig. 2c). The experiments were carried out on kaolin suspension of $0.1 \mathrm{wt} \%$ based on the previous results presented. $T$ increased with the rotation speed for both type I and II samples. The best results were obtained using the type II samples irradiated at $0.5 \mathrm{kGy}$. A correlation between flocculation results and physical/chemical characteristics of the obtained polyelectrolytes shows that even having modest values of $\eta_{\text {intr }}$ they exhibit in proper conditions, flocculation efficiencies in terms of transmittance up to $95 \%$. 



Fig. 1. Physical and chemical characteristics of polyelectrolytes type I and II.

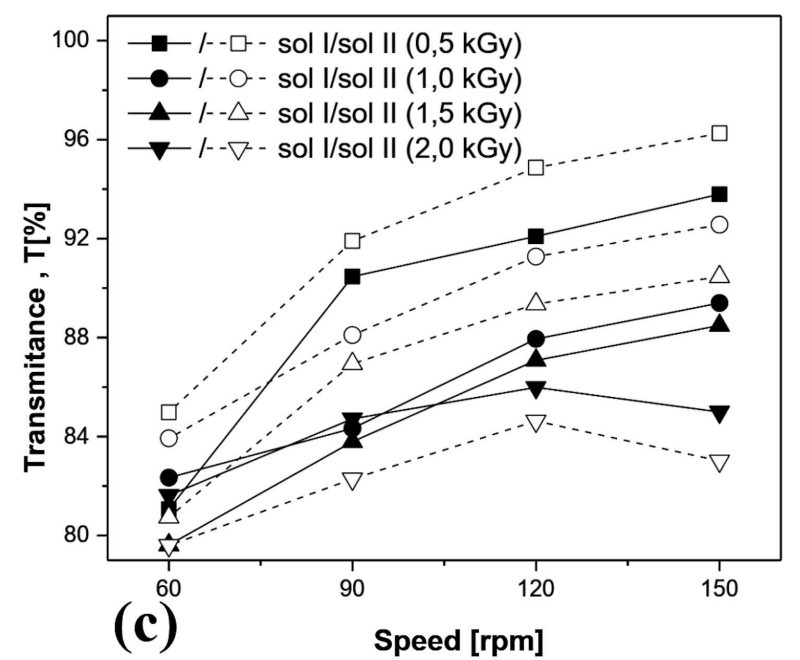

Fig. 2. Flocculation results based on the influence of: (a) $0.1 \mathrm{wt} \%$ kaolin suspension, (b) $0.2 \mathrm{wt} \%$ kaolin suspension and (c) the rotation speed. 


\section{Conclusion}

A new type of polyelectrolyte based on acrylamide, acrylic acid and sodium alginate for flocculation purposes was obtained by electron beam irradiation. Flocculation studies were made on kaolin suspension of 0.1 and $0.2 \mathrm{wt} \%$ with good results for polymer concentrations up to $5 \mathrm{ppm}$. The flocculation studies carried out on kaolin suspension of $0.1 \mathrm{wt} \%$ and in which the rotation speed was varied between 50 to $150 \mathrm{rpm}$ showed an increasing of transmittance with the rotation speed up to $95 \%$.

\section{Acknowledgments}

The researches were financed by the Romanian program NUCLEU - Contract No. 18.13.01.02.

\section{References}

[1] R.P. Singh, T. Tripathy, G.P. Karmakar, S.K. Rath, N.C. Karmakar, S.R. Pandey, K. Kannan, S.K. Jain, N.T. Lan, Curr. Sci. India 78, 798 (2000).

[2] IAEA Report of the 2nd RCM on Development of radiation-processed products of natural polymers for application in agriculture, healthcare, industry and environment, IAEA 2010.

[3] S. Al-Assaf, in: The Radiation Chemistry of Polysaccharides, Eds. S. Al-Assaf, X. Coqueret, K.Z.H.M. Dahlan, M. Sen, P. Ulanski, IAEA 2016, p. $5[20]$.

[4] G. Craciun, E. Manaila, M. Niculescu, D. Ighigeanu, Polym. Bull. 74, 1299 (2017).

[5] M.J. Caulfield, X. Hao, G.G. Qiao, D.H. Solomon, Polymer 44, 1331 (2003).

[6] A.K. Sarkar, N.R. Mandre, A.B. Panda, S. Pal, Carbohyd. Polym. 95, 753 (2013). 